\title{
ESTRUCTURAS RESISTENTES: SU SABIDURÍA PARA LA CIUDAD
}

Julio Martínez Calzón

Ingeniero de caminos, profesor de la Universidad Politécnica de Madrid

El autor desarrolla un argumento que relaciona los sistemas estructurales resistentes requeridos por los edificios y las infraestructuras urbanas con el pensamiento que en las distintas etapas de la modernidad ha regido los procesos urbanos.

primera vista resulta muy difícil,
desde la perspectiva de los sistemas
estructurales resistentes requeridos por los edificios o complejos que se integran en las ciudades, plantear o tratar de establecer una línea de pensamiento que se correlacione en propiedad y rigor con el título y argumento del ciclo «Moderno Posmoderno. Un siglo. Construir la ciudad, pensar la Metrópoli». Y sin embargo, no sólo se puede lograr tal acercamiento y encuadre, sino que desde su papel, un tanto nuclear o interno, sustantivo en muchos aspectos de otras áreas más lábiles, y no dañado en exceso o reducido por las incidencias de la cotidianeidad, la moda, etc., o al menos en muy poca medida sacado de su tarea constitutiva, resulta plenamente posible llevar a cabo un análisis muy preciso de los aspectos sociológicos, culturales, filosóficos, de desarrollo, etc.; en un palabra, urbanísticos. $\mathrm{Y}$ todo ello con una generalización y amplitud que desborda, como veremos, el inicial planteamiento estricto y conciso de dicho análisis.

Porque lo que aparentemente se ofrece como una línea de pensamiento muy ceñida a lo objetivo: las técnicas y ciencias de lo numérico en relación con: el cálculo; el conocimiento de los materiales; la aportación de la maquinaria y de los procesos constructivos; etc.; en la realidad profunda de sus planteamientos básicos y creativos, los sistemas estructurales plantan sus raíces, de manera intensa, en lo más hondo del ámbito subjetivo que impulsa el desarrollo de la Gran Cultura que, obviamente, nace y se desarrolla -para bien y para mal- en la ciudad. En un principio por el hombre aislado, ciudadano, o en pequeños grupos artesanales o académicos; hoy en enormes equipos, que han distorsionado de manera cataclísmica muchas de las líneas 
de sensibilidad que durante largos lapsos de tiempo originaron, primero, y nutrieron luego, el desarrollo y creatividad de todos los aspectos de la cultura antes mencionada, y en particular de los conceptos y análisis estructurales emergentes en el ámbito de la ciudad, que habían de impulsar sostenidamente las grandes realizaciones edificatorias de la misma.

Como primer argumento de sostén del axioma anterior, o primera regla, si se prefiere, de un lenguaje propio, debe figurar la fuerte tasa de crecimiento del número de edificios o construcciones que reclama hoy en día la necesidad de estructuras específicas; y del asimismo creciente y acelerado desarrollo de las demandas y requerimientos que se exigen a dichas estructuras, reflejo preciso y definido de la también creciente complejidad que afecta a las actividades, tanto de infraestructuras, como de organización de la ciudad de nuestro tiempo. Y este proceso se acrecienta aún más cuando las ciudades, en su natural crecimiento, tienden a establecer amplias conurbaciones de varios núcleos, aislados inicialmente, que llegan a conectarse o fundirse con otros próximos, generando un complejo entorno urbano; no todavía ciudad plena, en el sentido tradicional, pero con una trayectoria tendente a alcanzar la plena fusión y utilización combinada de sus recursos y posibilidades, de sus sinergias combinadas, podríamos decir.

Así pues, este crecimiento fulgurante de la ciudad reclama necesidades muy variadas que constituyen el ser de la neociudad de nuestro tiempo. Para tratar de atenernos al esquema del título anunciado acerca del siglo, se puede establecer una triple lista de consideraciones, en la que, en una parte, estarían las demandas de la sociedad tradicional moderna; en otra, las más o menos precisas solicitudes del actuar postmoderno; $y$, en una tercera, lo que yo desearía denominar simplemente ACTUALIDAD.

Este término me suscita filosóficamente un gran reto; y está poco establecido su potencial de ambitalidad, de juicio y de análisis, ligándose muy rápidamente bien al pasado reciente o al devenir inmediato, cuando ciertamente en sí mismo determina un pensamiento activo y crítico, que puede y debe analizarse muy en pormenor para lograr su pleno entendimiento.

Estimo que esta actualidad ha dejado ya totalmente de lado lo posmoderno y está embarcada en un nuevo orden de regulación y explotación de los numerosos parámetros que configuran el estar en realidad de hoy, que diría Zubiri. La estructura profunda de raíz filosófica que conforma el hoy, el presente, no es en modo alguno el concepto posmoderno de blandura y aceptación de esquemas pseudo modernos o clásicos, sino una neta interrogación sobre el propio tejido de actitudes generado en los tres o cuatro años recientes, que podrían conformar esa actualidad a la que me he referido. $Y$ esa interrogación se hace en clave de empleo de sistemas muy nuevos y diferentes que han surgido, en forma totalmente espontánea, a partir de la presencia activa de sistemas técnicos aislados, de carácter casi abstracto, pero aplicables muy directamente a procesos extremadamente concretos. Es decir, sistemas específicos que poseen en sí un potencial muy amplio de adaptación a 
otros procesos más complejos y al tipo de consideraciones claramente definibles como pertenecientes a una nueva realidad. Este proceso autónomo que, por sus interferencias, podría esquemáticamente denominarse neoempirismo, aunque incluyendo muy próxima a la experiencia una gran dosis de neoconceptualismo, será el que posiblemente regule tales procesos en el inmediato devenir de esa nueva realidad.

Estas consideraciones no están hechas desde el pensamiento abstracto filosófico, sino todo lo contrario: desde el propio proceso del desarrollo de las estructuras del que pretendo hablar.

Se aprecia también un segundo punto o regla del lenguaje de las estructuras en la ciudad y, por ende, de los procesos generales a los que antes me he referido. Dicha regla sería: la impulsión, desde abajo, de los aspectos netamente técnicos que exigen para su uso un cambio claro de los medios operativos (sistemas lógicos; materiales; maquinaria; etc.).

Y como inmediato tercer término, casi corolario del anterior, podría establecerse una absoluta transformación del ritmo y ajuste preferente no a las cosas, sino a los sistemas cambiantes. Cambio total del mundo de las cosas al mundo de las relaciones, en tiempo real; posible a través de los recursos informáticos. Es decir, manejo de los sistemas complejos como entes objeto, pero no cósicos, sino dinámicos y relacionales.

Finalmente, esto se traduce, al tratar de pensar sobre la ciudad, en la necesidad -cuarto argu- mento- de definir nuevas leyes para la misma; que han de establecerse para lograr un gran equilibrio entre los antedichos cambios procesales y las nuevas exigencias urbanísticas y edificatorias, de manera que se correlacionen en total profundidad las posibilidades abiertas por el nuevo lenguaje tecnológico y el cambiante papel de la ciudad, y lograr así un verdadero flujo operativo en el interior de los centros urbanos complejos.

En resumen, nos encontramos en este principio de siglo con un potencial inmenso de nuevas maneras de proceder en nuestros hechos, que deben llegar a estar neta y precisamente comprometidos con la consideración de la realidad como formada por unos nuevos objetos: no cósicos, sino profundamente dinámicos, cambiantes, relacionales; a través de un nuevo lenguaje, una nueva semántica, que regule esta naciente novel configuración de nuestro entorno psicofísico.

Antes de proseguir por esta senda hacia lo desconocido, convendría preguntarse, desde el punto de vista del hecho estructural y su enseñanza, dado que es lo que hoy, aquí, nos ocupa: ¿Qué era lo posible en el clasicismo previo a los setenta; es decir, en la última fase de lo que hemos titulado como movimiento moderno? La respuesta esquemática a tal cuestión podría estar basada en las siguientes líneas de actuación:

- Definición de sistemas estructurales con una gran lógica interna.

- Profundo análisis de los conceptos intrínse$\cos$ inherentes al hecho estructural; que podrían estar básicamente correlacionadas 
con las categorías del espacio, la materia, la energía y la forma.

- Máximo control del esquema estructural; de manera que pudiera ser tratado mediante sistemas de ecuaciones solventados mediante técnicas de relajación o algoritmos análogos (métodos de Cross, Kani, etc.); o por la integración o solución aproximada de sistemas de un número reducido de ecuaciones diferenciales.

- Procesos constructivos muy claros y de sencilla evolutividad.

- Reglas precisas de economicidad de la materia y la energía.

En términos sencillos podría decirse que lo importante del gran quehacer de aquel entonces radicaba en dos aspectos:

- Uno, aprovechar al máximo el concepto de brazo, como distancia entre fuerzas resultantes internas.

- Otro, utilizar en la mejor manera posible la forma, para establecer esquemas de flujo de fuerzas basadas en el arco (forma lineal) o en la membrana (forma superficial); en orden a favorecer la presencia de solicitaciones «fuertes»: axiles, frente a las «débiles»: flexión. Lo cual podría ser equivalente a establecer preferentemente sistemas intraslacionales; celosías basadas en la triangulación; uso del puntal y el tirante; etcétera.

Y por el contrario, total desapego de las formas complejas: líneas quebradas; curvas aleatorias o gratuitas; sólidos pseudo poligonales; etc.; para centrarse en la recta; las curvas soñadas o perfectas: círculo, parábola, catena- ria; el plano o las superficies también soñadas como perfectas: cúpulas esféricas o sencillas de revolución, membranas o superficies regladas; etc. Sistemas «duros» para transferencia de fuerzas y reducción de la inestabilidad: tirantes; superficies plegadas; sistemas arriostrados.

En una cierta forma lo que se buscaba era reducir el coste energético interno del sistema resistente mediante el empleo racional, «sabio», de los esquemas estructurales, vinculados lógicamente, debido a dicho racionalismo, a sistemas numéricos y matemáticos accesibles y relativamente sencillos y solubles; para sólo en casos algo especiales recurrir al ensayo en modelos.

En una palabra, dominio de la estática y de las teorías de primer orden, con un elevado aprovechamiento de la materia en el aspecto resistente.

No obstante, en este ámbito riguroso de las estructuras requeridas por las construcciones de la ciudad, también se dieron excepciones que parecen abrirse al futuro que nosotros ya conocemos: Tachira, e incluso el Frontón Recoletos de Torroja; el Estadio de Münich de Frei Otto y, posiblemente, la obra que, a mi entender, desmantela el período moderno, arquitectónica y estructuralmente hablando: La Ópera de Sydney (Utzon; Ove Arup).

Pero en general regía la Norma antes expresada y en la misma nombres como los previamente citados, y otros como: Buckminster Fuller, con sus cúpulas geodésicas y estructuras tensigrity autoequilibradas; Fred Severud; 
Le Messurier; Tsuboi; Lev Zetlin; L. Robertson; Schleich; Amman y Whitney; y más en el pasado Hennebique; Perret; Monier; Balcom; Ribera; Dischinger; representan la línea de pensamiento ingenieril que podríamos denominar como ortodoxa, que recorrió en máxima medida el mundo de las estructuras modernas aplicadas a la ciudad. El «dominio» era todavía precario, pero estos ingenieros hicieron suyas estas ideas y en buena medida, siempre muy laboriosamente, lo alcanzaron. Fueron grandes hombres y, en general, cultos.

Este gran período del pensamiento racional y analítico aplicado a las grandes estructuras se cierra, sin duda, con Fazlur Kahn, que en la década de los sesenta proporcionó a SOM (Skidmore, Owens, Merrill) el más alto fundamento que las estructuras podían aportar al diseño de los edificios de gran altura y que significaron, en cierto modo, el formidable y maravilloso canto del cisne de una época trascendente en el empleo racionalizado de las estructuras en la arquitectura.

Y como cierre y colofón de todo lo anterior, me interesa señalar que, desde mi personal apreciación, la obra de Mies Van der Rohe me parece la más perfecta integración de todo lo que significan por separado la arquitectura y la ingeniería de estructuras, y me suscita la máxima reverencia en su sencillez. En verdad podría ser el símbolo o paradigma de lo que aquí ha querido expresarse dentro del ámbito del movimiento moderno.

La fase de los ochenta, a mi entender sede del posmodernismo, precedido en los setenta por el estilo denominado por algunos críticos de arquitectura como tardomoderno, desaprovecha en gran medida los recursos emergentes que la técnica y los nuevos conocimientos iban produciendo, para destinarlos a un pensamiento blando, volátil, que por supuesto creó obras de interés particular, pero que, en general, condujo a subproductos estructurales, que se las vieron y desearon para ceñirse a los conceptos formales que debían sustentar.

Período de reduccionismo claro del pensamiento estructural. Compás de espera de lo que sería el desarrollo práctico, mediante los grandes y veloces ordenadores, del análisis matricial y del cálculo numérico; y el empleo de las lógicas no formales en el ámbito del análisis.

Mi particular periplo, afortunadamente para mí, no se desarrolló en estos ámbitos bastante confusos, sino que al elegir investigar acerca de una técnica nueva: las estructuras mixtas, pude eludir esa confusión, concentrándome en su conocimiento teorético riguroso y en la realización de obras totalmente vinculadas al aprovechamiento profundo de esta técnica estructural; mediante una utilización muy ajustada, que atendiera a su origen y propiedades específicas. Y para ello consideré como fundamental la aplicación de conceptos culturales clásicos, premodernos, desde luego totalmente alejados de la temática postmodernista, como lo atestiguan algunas de las obras que luego les mostraré.

Algunos casos podrían considerarse como leves incursiones en el ámbito de lo posmoderno; es decir, utilización de la ficción, el engaño, la apariencia; pero siempre como 
colofón neto; que se adopta como añadido al esquema profundo conceptual subyacente, pero nunca como origen o inicio de la actividad creadora o conformadora. $\mathrm{Y}$, por supuesto, las estructuras siempre muy situadas en el aspecto moderno de máxima racionalización de su conocimiento y soportes constructivos.

La fase actual, basada plenamente en el empleo de superprogramas de cálculo, representación, dibujo asistido, etc., determina sin lugar a dudas un cambio neto y sustancial del pensar estructural.

El conocimiento se mantiene sin cambios, pero los límites impuestos por la impotencia ceden ante el dominio del comportamiento de la materia y sus formas resistentes; y los esquemas estructurales al uso se ven desbordados por la pasión de las posibilidades formales y constructivas, dando lugar a un verdadero pandemónium de procesos, programas, posibilidades, etc.

Las estructuras se estilizan en sentido estructural, penetrando en territorios antes sólo bordeados, cuando mucho: el análisis no lineal, el control dinámico, los sistemas inteligentes, los materiales mutantes, los dispositivos amortiguadores, etcétera.

Hemos entrado en una etapa de «dominio», iniciándose con ella el abarcar formas, sistemas, procesos constructivos, disposiciones, etc., impensables en los años posmodernos porque todavía no habían cristalizado los medios de ese lenguaje a que antes aludía.

Ahora, el peligro viene del «sobredominio». Instalados en un falso dominio, muchos técnicos se arrojan al vacío de la utilización sin conocimiento, basado solamente en un cierto control numérico de los fenómenos estructurales, que en modo alguno es correlativo del hecho o del verdadero comportamiento resistente, porque debe mediar el control sobre los esquemas reales de los vínculos, de las coacciones, de los procesos deformativos no perfectamente representables. Las estructuras ya no son tan fáciles de catalogar, porque encierran y engloban multitud de líneas, de posibilidades, de conceptos deformativoresistentes. Y tampoco de enjuiciar, porque se superan las condiciones de intuición y conocimiento de los citados técnicos.

Pero no todo esto resulta negativo y creo que el tiempo, al decantarse el magma de esta erupción, permitirá arribar a una nueva playa de orden, de corrección, en suma, de cualidad; apreciando precisamente la sabiduría propia de las estructuras y su perfecta aplicación a la ciudad de este siglo que se abre ante nosotros lentamente.

A la vista de todo lo anteriormente expuesto la triple lista antes mencionada podría expresarse así: 


\section{EDIFICIOS Y ESTILOS EN EL SIGLO XX}

\author{
MODERNO \\ $\cong 60$ 's \\ (PODER)
}

\section{Edificios de altura}

Resolución posibilista; procesos ajustados al esquema analítico.

\section{Grandes edificios públicos}

Prestigio de las ciudades y estados, en conformidad a un cierto control.

\section{Edificios religiosos}

Última fase de un ciclo; salvo en países del tercer mundo y emergentes o con necesidades de coacción.

\section{Edificios culturales y docentes}

Gran final de un período que centra en el conocimiento estático, cartesiano, su afán de superación.

\section{Edificios deportivos}

Impresionante culto a los grandes eventos pero aún dentro del esquema clásico del estadio o del pabellón racional, riguroso. Pocas posibilidades para uso de instalaciones de calidad por el ciudadano.

\author{
POSMODERNO \\ (Manierismo moderno) \\ $\cong 80$ 's \\ (MANIPULACIÓN Y JUEGO)
}

Manipulación y ruptura de la forma basado en la pseudoclasicidad. Banal (No se dominaba el nuevo modelo).

Pérdida de referencias y reduccionismo de los modelos, por miedo y falta de preparación de los directivos.

Tendencias hacia el escapismo y mezcla de actitudes sagradas y profanas encuadradas en sectas y pensamientos irracionales.

Pérdida de la fe en el conocimiento y la cultura; adaptaciones a lo gestual y directo; nulo rigor. Simples datos como cultura de masa.

Esquematización de los aspectos anteriores en un flujo/reflujo de rechazo/utilización de las grandes reuniones y mística de las masas. Abandono del deporte personal por el ciudadano.

\author{
ACTUAL \\ (Neoconceptualismo) \\ $\simeq \mathbf{2 0 0 0}$ \\ (EFECTISMO \\ ESCULTORICISTA)
}

Se trata de alcanzar valores de encantamiento mediante las formas abiertas, desencadenadas por el dominio del análisis y los procesos.

Elementos cada vez más emblemáticos y de un enorme derroche provocado por funcionarios poco cultos; se atisba una fase de mayor dominio y aprovechamiento de las nuevas posibilidades.

Directivos de nueva formación.

Práctica transformación hacia el cambio absoluto seglar-comerciaempresarial. La empresa $\cong$ activa Iglesia actual.

Establecimiento de la nueva educación; en inicio basada en el empleo de la información deducida del tratamiento potente de los datos. La nueva escuela semi o totalmente electrónica. Grandes ejemplos museísticos, bibliotecas, etc., como pseudo atracciones culturales.

Clara tendencia a la manipulación económico-comercial mediatizada por la televisión.

Impresionantes despliegues operativos en los grandes eventos: Olimpiadas y Campeonatos Mundiales de los deportes dominantes.

Proliferación de centros de calidad para el uso deportivo ciudadano. 


\section{MODERNO}

\section{Centros comerciales}

Las grandes galerías

significativamente vinculadas en

sus imágenes a las grandes

Estaciones y centros de transporte.

\section{Torres y monumentos}

Racionalismo y cierta importancia ideológica.

\section{Transportes}

Sistemas de superficie y en lo posible subterráneo, con obras austeras y unidas a las posibilidades económicas y de financiación.

ACTUAL

Proliferación de los centros comerciales de tipo hipermercado magnificado.

Abandono de los conceptos basados en la exposición de símbolos creadores de identidad.

Importante llamada teórica a los transportes colectivos absolutamente desoída.
Democracia supeditada hacia un cierto.

Despotismo ilustrado
Democracia desavenida, con rupturas en nuevas capas de clara exclusión social.

Descontento no constructivo
Presencia de grandes centros comerciales (Malls) que reúnen el ocio, la cultura, la venta, el semideporte; de manera de crear fidelidad y atracción. Positiva y creciente incidencia de la interacción electrónica.

Impresionante despliegue de elementos monumento de carácter simbólico de lo técnico y lo empresarial.

La diversión como valor.

Potencialización de los sistemas viales en tres dimensiones y subsistemas, para resolver los crecientes requisitos de funcionamiento de la ciudad de hoy. Insuficiencia por la presión del vehículo privado. El trabajo en casa y la desagrupación del tiempo de descanso como métodos de desarrollo complejo.

Espectacularidad de los lugares de intercambio y uso; en la línea de socialización de los recursos pero en otra dirección que en el pasado (Metro de Moscú).

Democracia formal encadenada. Totalitarismo económico banal, con un estrato porcentuaimente creciente de gran cultura y formación.

Máximo impulso exhibicionista. 
Las estructuras en la ciudad de hoy muestran tan sólo su sabiduría durante el proceso constructivo. Ahí expresan en gran medida el dominio de las posibilidades resistentes de la materia y el poderoso despliegue de los medios y procesos industriales del presente. Yo confío que en breve plazo sepamos decantar la nueva belleza que los medios técnicos de computación nos brindan, a través de esa sabiduría que la materia estructural nos ofrece y lleguemos a alcanzar un nuevo rigor basado en el control conceptual, desde dentro, de esa fantasía personalista que ahora nos desborda.

Para ello será necesario desplegar una ética diferente, ajustada con toda precisión al modo de actuar de la razón práctica profunda que, con toda seguridad, nuestro tiempo posee pero aún no hemos sabido determinar.

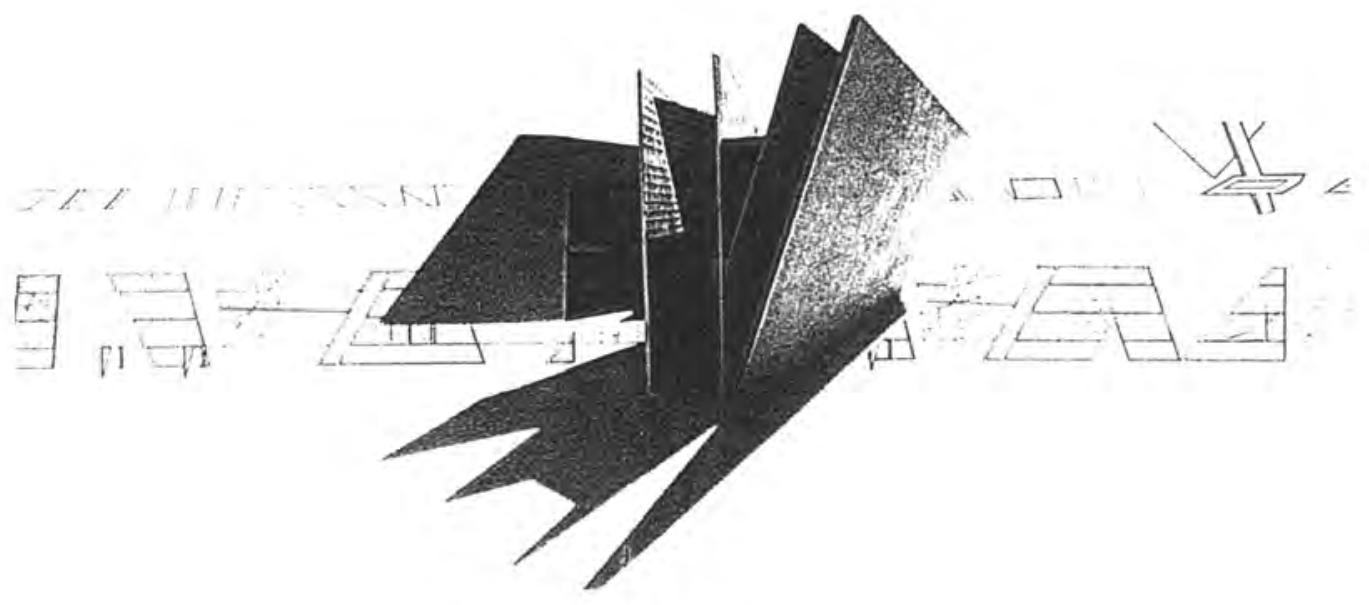



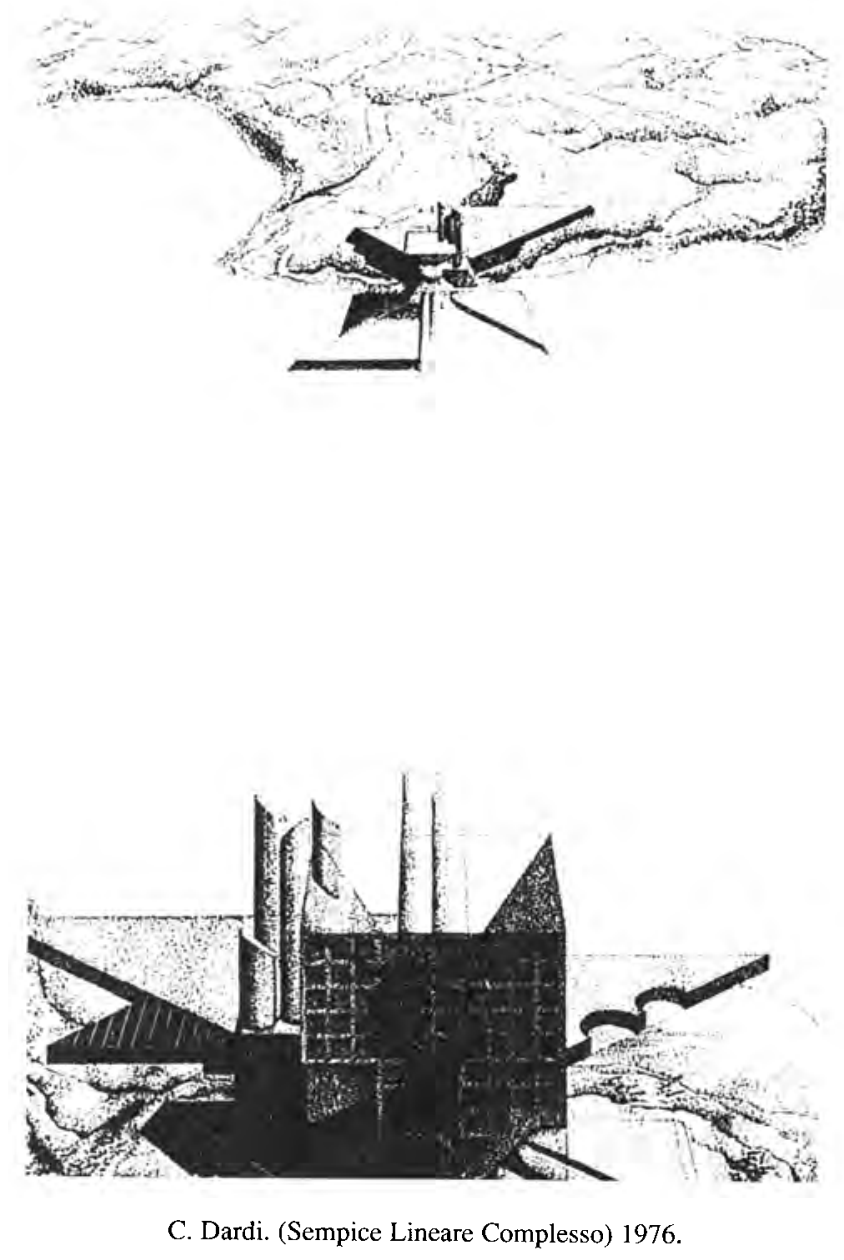